\title{
Assessment of sustainable development factors of the old industrial region: the case of the Ural Federal Okrug
}

\author{
Irina Rakhmeeva, and Evgeniy Animitsa \\ Ural State University of Economics, 8 Marta/Narodnoy Voli St., 62/45, 620144 Ekaterinburg, Russia
}

\begin{abstract}
The sustainability of the development of old industrial regions is under threat during the 4th industrial revolution. Social, institutional and innovative factors are becoming critical for development in addition to task of solving environmental problems. The article describes methods of assessment of sustainable development factors of the old industrial region. The old industrial regions of the Ural Federal Okrug became the field for approbation of method. Results of analysis showed the preservation of environmental threats and food security of Ural regions. The Sverdlovsk and Chelyabinsk regions demonstrated a high level of development of the industry and regulatory environment, and sufficient financial independence. Subsidized dependence, the decline of industry and bad regulation characterize the Kurgan region. Thus, a high quality of regulatory environment and level of development of social sphere, innovative orientation of the economy ensure the sustainable development of the Sverdlovsk and Chelyabinsk regions. Low parameters of sustainability factors for the Kurgan region keep it in the trap of socioeconomic failure. The research confirms the hypothesis of a high correlation of factors and their influence on regional development. The conclusions have practical significance for regional authorities and development corporations.
\end{abstract}

\section{Introduction. The paradigm of sustainable development}

The first quarter of XXI century is the time of fourth industrial revolution. This period gave humanity rapid technological development with changing relationship in all spheres of human life and turbulence of economic and social processes. The industrial revolution made shift in development factors. Thus, the task of finding new approaches for sustainable development of territories became actual.

From the author's point of view, the old industrial regions have the strongest problem of disbalance of development.

Sustainable development includes the complex simultaneous promotion of various characteristics of the territory. All factors influence each other, for example, experts found correlations between social and environmental sustainability [1], industrial and environmental development [2], etc. At the same time, the balance of development factors ensures the sustainability of development. 
The author considers that is correct to attribute internal reserves and potential of the region to the factors of sustainable development of the territory. External factors (for example, economic and political shocks) operate everywhere. Internal factors determine the region's ability to resist external shocks and impacts.

Let's consider the system of sustainable development factors by sections.

1. Financial and economic factors are budget security and dependence on transfers from the Federal budget [3], the level of investment [4], and involvement in national and global markets.

2. Innovation and production factors include the availability of production facilities, material resources, the level of energy independence [5], educational, scientific and engineering centers, the level of inventive and innovative activity, the level of development of transport, communication, market and innovation [6] infrastructure.

3. Environmental and geographical factors embrace natural and climatic conditions, geographical location, agglomeration effects [7] and the level of technogenic pollution [2].

4. Food security is characterized by the state of agriculture in the region, including processing enterprises $[8,9]$, as well as the coverage of commercial enterprises.

5. Social factors concern availability of qualified labor resources and jobs, developed social sphere [10], activity of public organizations.

6. Institutional factors involve the level of extractivity / inclusiveness of the institutional (regulatory) environment, the positioning of the region (brand) on a national and global scale, the level of corruption and government openness.

The role of human capital, innovation infrastructure, and the institutional environment increases during the fourth industrial revolution. Material-intensive production is becoming less competitive in comparison with technologies 5 and 6 of the technological order. The level of digitalization of production and public administration begins to determine the prospects for the development of the territory [11].

Old industrial regions are characterized by a developed industrial basis, extensive production and environmental problems traditionally. Climate change poses an additional threat [12]. Often the transition to the technologies of the new technological order does not occur, the economy of these regions is extractive and based on the old technological order. The author's hypothesis is following. A factor of the long-term development of oldindustrial regions is the creation of a regulatory environment that promotes the transition to innovative development and the practical implementation of advanced technologies.

\section{Methods of assessment of sustainable development factors of the old industrial region}

The author suggests to create a profile of sustainable development factors. Each axis of the profile shows the state of the factor in 6 described directions. Table 1 contain the scale and basis for expert assessment of the factors.

Table 1. Scale for compiling a profile of sustainable development factors

\begin{tabular}{|l|c|}
\hline \multicolumn{1}{|c|}{ Mark } & Basis \\
\hline High sufficiency of factor & $\begin{array}{c}\text { Entering the region in the first third of the rating of regions } \\
\text { by factor indicators }\end{array}$ \\
\hline Medium sufficiency of factor & $\begin{array}{c}\text { Entering the region in the second third of the rating of } \\
\text { regions by factor indicators }\end{array}$ \\
\hline Low sufficiency of factor & $\begin{array}{c}\text { Entering the region in the last third of the rating of regions } \\
\text { by factor indicators }\end{array}$ \\
\hline
\end{tabular}


3 old industrial regions are located on the territory of the Ural Federal Okrug (district). These are the Sverdlovsk, Chelyabinsk and Kurgan regions. They provide a suitable field for analysis the sustainability profile of old industrial regions.

\section{Results and Discussion}

The issue examined official statistics that indicate the state of the old industrial regions of the Ural Federal okrug.

1. The Chelyabinsk and Sverdlovsk regions are in the middle of the list in terms of investment per capita (74.4 thousand rubles and 73.6 thousand rubles against the national average of 119.8 thousand rubles) at the end of 2018. Both regions have a fairly balanced budget and actively attract Federal investment for development projects. Kurgan region is the second from the end of the rating in terms of investment per capita and is highly dependent on subsidies region.

2. The Sverdlovsk region has been among the top 10 regions in terms of gross regional product for many years. The Chelyabinsk region is slightly inferior to the Sverdlovsk region, remaining among the 15 leading regions. But the Kurgan region is traditionally in the last 20 of the list. However, GRP per capita in 2017 was lower than the Russian average in all 3 regions (495.1 thousand rubles in the Sverdlovsk region, 385.6 in the Chelyabinsk region and 236.4 in the Kurgan region against 510.3 thousand rubles in Russia).

In 2018, the Sverdlovsk region ranked 4th among Russian regions in terms of manufacturing production and 4th in terms of electricity production. Chelyabinsk region took 7 th and 12th place relatively. The Kurgan region was in the last third of the list in terms of all indicators.

The Sverdlovsk and Chelyabinsk regions are distinguished by a large number of specialized educational institutions of various levels, strong scientific and engineering schools. This allowed the Chelyabinsk region to become a leader in the number of advanced production technologies developed. At the same time, the region is only in the middle of the list (44th place) in terms of the level of innovation activity of organizations (the share of organizations that implemented technological innovations). The Sverdlovsk region took the 6th place and 24th place in similar indicators. Kurgan region is in the last third again.

Thus, it is possible to estimate the innovation and production factor for the Sverdlovsk and Chelyabinsk regions as the maximum, and for the Kurgan region as the minimum.

3. All three regions traditionally completing the list of National ecological rating. Longterm extensive polluting production creates high risks for the ecology of old-industrial regions. Ongoing measures to eliminate accumulated damage do not give the expected effect.

4. The level of self-sufficiency of the population of the Sverdlovsk region of the main agricultural products in 2017 were for milk and dairy products - 66,6\%, meat and meat products $-56,2 \%$, eggs and egg products $-101,8 \%$ potato $-86,6 \%$, vegetables $-40,2 \%$, fruit and berries of $13.2 \%$.

The level of self-sufficiency of the Chelyabinsk region is $315 \%$ for bread products, $119 \%$ for potatoes and vegetables, $147.0 \%$ for meat, and $137.5 \%$ for eggs. A shortage of milk is $63 \%$. Up to $80 \%$ of pasta, $50 \%$ of flour, and $45 \%$ of meat produced in the Chelyabinsk region are exported to other regions of Russia and abroad.

The level of self-sufficiency of the Kurgan region for grain is $169.8 \%$, for potatoes is $103.3 \%$, for vegetables is $99.7 \%$, for meat is $77.0 \%$, for milk is $97.5 \%$, for eggs is $46.7 \%$.

5. Real incomes of the population of 3 regions have been falling since 2013. The Sverdlovsk region is in the top 20 in terms of the average per capita income, the Chelyabinsk region is in the middle, and the Kurgan region in the last 10 regions of Russia. 
The share of the population with monetary incomes below the subsistence minimum in the Kurgan region is $19.6 \%$, the 11 th place among the poorest regions. In the Sverdlovsk and Chelyabinsk regions, the corresponding indicator is $9.5 \%$ and $12.8 \%$ (the average for Russia is $12.6 \%$ ). The unemployment rate in the Sverdlovsk region is $4.8 \%$ and equal with the national average, rate in the Chelyabinsk region is $5.6 \%$, rate in the Kurgan region is $8 \%$.

The Sverdlovsk and Chelyabinsk regions are in the first third regions in terms of the capacity of outpatient clinics (visits per shift per 10,000 people), the availability of places for preschool children, and the number of institutions of secondary and higher professional education. Kurgan region is in the second half of the list of regions by all indicators.

Thus, the author estimates the social stability factor of the Sverdlovsk region as high, the Chelyabinsk region as medium, and the Kurgan region as low.

6. The author assessed the state of the regulatory environment in the Ural macroregion in an earlier research [13]. The results showed the similarity of the informal institutional environment of the 3 regions. Historical and geographical connectivity explains this fact. The quality of the legal environment varies significantly. The regulatory environment for industrial development and innovation is most favorable in the Sverdlovsk region, mediumlevel in the Chelyabinsk region, and low-quality in the Kurgan region.

Figure 1 shows complex profile of the sustainable development factors of the Ural old industrial regions.

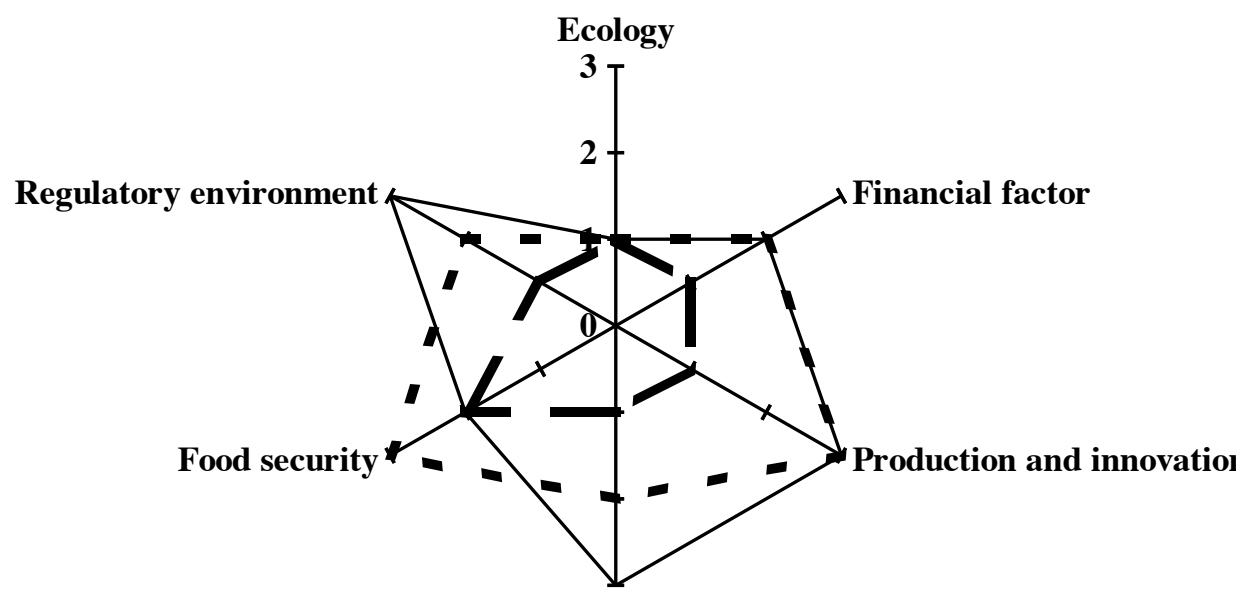

Social factor

\section{- Sverdlovsk region - - Chelyabinsk region $\quad$ Kurgan region}

Fig. 1. The profiles of the sustainable development factors of the regions of the Ural Federal Okrug

Results of analysis of the sustainable development factors of the regions of the Ural Federal Okrug showed the preservation of environmental threats to the development of old industrial regions and food security simultaneously. The Sverdlovsk and Chelyabinsk regions have a high level of industrial development and sufficient financial independence. Subsidized dependence and the decline of industry is in the Kurgan region. We observe a significant differentiation in the quality of the institutional environment and social factors of development in 3 regions. 


\section{Conclusion}

The research confirms the author's hypothesis about the high correlation of factors and their influence on regional development.

An environmentally unfavorable situation often accompanies old-industrial regions. It happened in the article's case too. Increasing the share of innovative production based on green (environmental) technology will not worsen the environment. However, more attention needs to be paid to restoring air, soil and water quality. Their condition determines the health and quality of life of the population. This affects the social factor of sustainability in turn. Advanced technologies, such as bioenergy [14], will allow to solve the problems of providing energy simultaneously.

The high quality of the regulatory environment and level of development of the social sphere, and the innovative orientation of the economy ensure the sustainability of the development of the Sverdlovsk and Chelyabinsk regions. Low parameters of sustainability factors for the Kurgan region keep it in the trap of socio-economic failure.

Regional authorities should ensure the comprehensive development of all factors for the sustainable development of old-industrial regions in the context of the fourth industrial revolution. However, the main focus should be on the institutional environment for the formation of a new type of society $[15,16]$ and the restructuring of the economy on the basis of 5 th and 6 th technological orders.

\section{References}

1. W.N. Adger, Progress in Human Geography, 3, 347 (2000)

2. O.Yu. Voronkova, L.A. Yakimova, I.I. Frolova, Ch.Ya. Shafranskaya, S.G. Kamolov, Prodanova N.A., International Journal of Economics and Business Administration, 2, 151 (2019)

3. V.V. Klimanov, S.M. Kazakova, A.A. Mikhaylova, Regional Science Policy and Practice (2020)

4. N.D. Dmitriev, M.V. Kudryavtsev, Modern Science, 4-1, 73 (2019)

5. L.S. Belyaev, O.V. Marchenko, S.P. Filippov, S.V. Solomin, T.B. Stepanova, A.L. Kokorin, World energy and transition to sustainable development (Boston/Dordrecht/London, 2002)

6. N.V. Lyasnikov, M.N. Dudin, V.D. Sekerin, M.Ya. Veselovsky, V.G. Aleksakhina, Life Science Journal, 6, 535 (2014)

7. E.G. Animitsa, Economy of Region, 1(29), 231 (2012)

8. E.B. Dvoryadkina, E.A. Belousova, Espacios, 39 (2018)

9. V. Trukhachev, A. Ivolga, M. Lescheva, Sustainability, 1, 164 (2015)

10. V.K. Levashov, Sotsiologicheskie issledovaniya, 4, 3 (1997)

11. A. Agumbayeva, E. Chmyshenko, N. Pulyaev, D. Bunkovsky, K. Kolesov, E. Amirova, Journal of Advanced Research in Law and Economics, 6 (44), 1861 (2019)

12. S. Bauer, I. Scholz, Climate and Development, 2, 83 (2010)

13. I.I. Rakhmeeva, R-economy (to be published)

14. C.M. Lee, M. Lazarus, Climate and Development, 4, 305 (2013)

15. S.D. Bodrunov, Upravlenets - The Manager, 5, 2 (2019)

16. S.B.D. Goldberg-Miller, J.L. Nasar, J.R. Meyer, Journal of Urbanism: International Research on Placemaking and Urban Sustainability, 13(3), 357 (2020) 